\title{
EVALUATION OF ENTRAPMENT EFFICIENCY OF GLIPIZIDE MICROSPHERE
}

\author{
${ }^{1}$ Arora Neha, ${ }^{2}$ Khattar Himanshi, ${ }^{2}$ Parashar Deepa,${ }^{1}$ Arora Nageen,,${ }^{3}$ Garg Tarun \\ ${ }^{I}$ Department of Quality Assurance, I.S.F. College of Pharmacy, Moga, Punjab. \\ ${ }^{2}$ Department of Pharmaceutics, I.S.F. College of Pharmacy, Moga, Punjab. \\ ${ }^{3}$ Department of Pharmaceutics, Seth G.L.Bihani S.D. College of Tech. Edu., Sriganganagar.
}

\section{INTRODUCTION}

Glipizide is a second-generation sulfonylurea that acutely lowers the blood glucose level in humans by stimulating the release of insulin from the pancreas and it is prescribed to treat type II diabetes (non-insulindependent diabetes mellitus). Its short biological half-life (3.4 60.7 hours) necessitates that it be administered in 2 or 3 doses of 2.5 to $10 \mathrm{mg}$ per day.18 Thus, the development of controlled-release dosage forms would clearly be advantageous. So we have formulated oral controlledrelease products of glipizide by various techniques ${ }^{1,2}$.

Moreover, the site of absorption of glipizide is in the stomach. Dosage forms that are retained in the stomach would increase the absorption, improve drug efficiency,and decrease dose requirements. Thus, an attempt was made in this investigation to use chitosan as a mucoadhesive polymer and prepare microspheres ${ }^{3,4}$.

\section{MATERIAL AND METHOD \\ Material}

Eudragit RS 100 was obtained from Loba chemicals.Glipizide was obtained as gift sample from Dr. Reddy's Laboratory Ltd., Hyderabad (India)., Magnesium Stearate, Liquid paraffin, Dioctyl phthalate, Diisobutylpthalate all chemicals are used of analytical grade were purchased from Loba Chemicals Pvt. Ltd., Mumbai (India).

\section{Method}

Glipizide microspheres were prepared by solvent evaporation techniques5-7. Different amounts of Eudragit@ RS were dissolved in $8.5 \mathrm{ml}$ acetone separately by using a magnetic stirrer. Glipizide, was added to the polymer matrix and mixed for 15 minutes, followed by magnesium stearate $(100 \mathrm{mg})$ after that these all chemical were mixed thoroughly. The resulting dispersion was added to a mixture of $90 \mathrm{ml}$ light liquid paraffin and $10 \mathrm{ml} \mathrm{n}$-hexane contained in a $250 \mathrm{ml}$ beaker, while stirring at $700 \mathrm{rpm}$ using a mechanical stirrer .Stirring was continued for $3 \mathrm{~h}$ until the acetone evaporated completely. The microspheres formed were filtered using Whatman no. 1 filter paper $^{1-3}$. The residue was washed 4-5 times with $50 \mathrm{ml}$ portions of n-hexane. The product was then dried at room temperature for 24 hours. Formulation without plasticizer were coded by B1, B2, B3 and B4, B5 which having different drug:polymer ratio 1:1.5,1:2,1:3,1:4,1:5 respectively. Formulation with plasticizer were coded by F1, F2, F3, F4, F5 having same concentration of polymer but different concentration of Diisobutylpthalate and Dioctylpthalate.

\section{PERCENT YIELD AND ENTRAPMENT EFFICIENCY}

Prepared microspheres were weighed after drying, and percent yield was calculated using following Formula Percentage Yield $=($ Actual weight $\mathrm{x} 100) /$ Theoretical Weight

Microspheres of known weights were stopper tightly in a flask containing $50 \mathrm{ml}$ of $6.8 \mathrm{pH}$ phosphate buffer. The flasks were shaken using orbital shaker for 48 hours to break the beads completely. After 48 hours the solution was filtered using whatman's No. 1 filter paper and the filtrate was centrifuged using a tabletop centrifuge to remove the polymeric debris.Then the polymeric debris was washed twice with fresh solvent (water) to extract any adhered drug. The clear supernatant solution was then analyzed for glipizide content by a UV spectrophotometer (JASCO-V500, Japan) at the $\lambda$ max value of $275 \mathrm{~nm}^{5-7}$. The complete extraction of drug was confirmed by repeating the extraction process on the already extracted polymeric debris. The $\%$ entrapment efficiency of the matrix was then calculated as \% Entrapment efficiency $=$ (Drug loading /Theoretical drug loading) x 100 .

\section{Result \\ ENTRAPMENT EFFICIENCY}

The percentage entrapment efficiency of eudragit coated glipizide (with plasticizer) microspheres were as given in Table 1.for batch f1 to f5. Entrapment efficiency for formulation F5 (80\%) was maximum and minimum for formulation F1 (45 $\%)$. It was observed that use of plasticizers increased entrapment efficiency of glipizide. For formulations with DOT as plasticizer Entrapment efficiency was comparatively more than with DIBT. Again as concentration of plasticizers increases percentage entrapment efficiency of glipizide increases. It may be because with increase in plasticizer concentration increases crosslinking which leads to increases in drug holding capacity. And the percentage efficiency of eudragit coated glipizide (without plasticizer) microsphere wer as given in table 2 for batch B1-B5.It was observed that on increase concentration of 
polymer entrapment efficiency was also increased. Entrapment efficiency for formulation B5 was (83\%) was maximum and minimum for formulation B1 was $50 \%$.

Table 1: Entrapment efficiency of different Drug:E-RS100:Plasticizer

\begin{tabular}{|l|l|l|l|l|}
\hline Batch code & Drug:E-RS100 & DOT & DIBT & Entrapment efficiency \\
\hline F1 & $1: 5$ & --- & ---- & $45 \pm 1.5$ \\
\hline F2 & $1: 5$ & ---- & 15 & $60 \pm 1.8$ \\
\hline F3 & $1: 5$ & & 25 & $75 \pm 0.3$ \\
\hline F4 & $1: 5$ & 15 & ---- & $69 \pm 1.2$ \\
\hline F5 & $1: 5$ & 25 & ----- & $80 \pm 0.6$ \\
\hline
\end{tabular}

DOT: Dioctylpthalate, DIBT: DiIsobutylpthalate

Table 2: Entrapment efficiency of different Drug:E-RS100

\begin{tabular}{|l|l|l|}
\hline Batch code & Drug:E-RS100 & Entrapment efficiency \\
\hline B1 & $1: 1$ & $50 \pm 1.3$ \\
\hline B2 & $1: 2$ & $59 \pm 1.8$ \\
\hline B3 & $1: 3$ & $65 \pm 0.4$ \\
\hline B4 & $1: 4$ & $70 \pm 1.2$ \\
\hline B5 & $1: 5$ & $83 \pm 0.2$ \\
\hline
\end{tabular}

\section{CONCLUSION}

Glipizide microspheres were prepared by solvent evaporation technique using Eudragit RS 100 as a matrix polymer with dibutyl phthalate and diethyl phthalate as plasticizers and also witout plasticizer. As we Increased in concentration of plasticizers ,the percentage entrapment efficiency of glipizide was increased. Furthermore these microspheres can be orally administered using capsule as a dosage form which will be ideal to maintain sustained release of glipizide.

\section{REFERENCES}

1. T.W. Chung, Y.Y. Huang, Y.Z. Liu, Effect of the rate of solvent evaporation on the characteristics of drug loaded PLLA and PDLLA microspheres, Int J Pharm,212, 2001, 161-169.

2. J. Wang, S.P. Schwendeman, Mechanism of solvent evaporation encapsulation processes: prediction of solvent evaporation rate, J Pharm Sci,88, 1999,1090-1099.

3. A.G. Thombre, A.R. Denoto, D.C. Gibbes, Delivery of glipizide from asymmetric membrane capsules using encapsulated excipients, J Control Release,60, 1999,333-341.

4. K.P.R. Chowdary, G. Balatripura, Design and in vitro evaluation of mucoadhesive controlled release oral tablets of glipizide, Ind J Pharm Sci.,65, 2008,591-594.

5. B.H. Woo, G. Jiang, Y.m.W Jo, P.P. DeLuca, Preparation and characterization of a composite PLGA and poly (acryloyl hydroxymethyl starch) microsphere system for protein delivery, Pharm Res.,18, 2001,16001606.

6. K.P.R. Chowdary, R.N. Koteshwara, K. Malathi, Ethyl cellulose microspheres of gliplizide: characterization, in vitro and in vivo evaluation, Indian Journal of pharmaceutical sciences,66, 2004, 412416.

7. S.K. Sahoo, A.A. Mallick, B.B. Barik, P.C. Senapati, Formulation and in vitro Evaluation of Eudragit ${ }^{\circledR}$ Microspheres of Stavudine, Tropical Journal of Pharmaceutical Research,4, 2005,369-375. 